\title{
A Literature Review on the Evidence and Limitation for the AMH Theory
}

\author{
Zhaoyu $\mathrm{Li}^{1, \mathrm{a},{ }^{,}, \dagger}$ Rui $\mathrm{Li}^{2, \mathrm{~b},{ }^{*}, \dagger}$ Boning Xiao ${ }^{3, \mathrm{c},{ }^{*}, \dagger}$ \\ ${ }^{1}$ College of economy and trade, Zhongkai University of Agriculture and Engineering, ZHKU, Guangzhou, China \\ ${ }^{2}$ College of Economics and Management, Tianjin University of Science and Technology, TUST, Tianjin, China \\ ${ }^{3}$ School of Economics, Beijing Technology and Business University, BTBU, Beijing, China \\ *Corresponding author.Email: ${ }^{a} z h a o y u \_l i @ f o x m a i l . c o m{ }^{b}$ RayLi1999@163.com ${ }^{c} 1702040223 @$ st.btbu.edu.cn \\ These authors contributed equally.
}

\begin{abstract}
It remains a challenge for the Adaptive Market Hypothesis (AMH) to reconcile Efficient Market Hypothesis (EMH) with behavioural finance. This paper reviews many previous papers and examines AMH whether it is consistent with real changes in markets. By examining previous studies on the relationship between AMH and EMH, this paper summarizes the efficiency of different types of markets in different countries to prove Adaptive Market Hypothesis. In most stock markets, bond markets, foreign exchange markets and other relevant markets, the changes of efficiency overtime are consistent with implication of AMH. However, there are still limitations of AMH which cannot well explain the efficiency of crude oil markets. Furthermore, it is criticized being a qualitative model instead of a quantitative model. This research enables us to better understand the theory of AMH as well as its application and limitation.
\end{abstract}

Keywords: Adaptive Market Hypothesis, Efficient Market Hypothesis, Application, Limitation, Market efficiency.

\section{INTRODUCTION}

The Adaptive Market Hypothesis (AMH) is an advanced theory to explain the existing market anomalies and the variation of markets and investment strategies efficiency. Lo proposed this theory based on an evolutionary perspective [1]. In this new theory, Lo states that market efficiency varies with time and market conditions. Investors have to learn and adapt to reinforce their abilities for surviving in the dynamic market. If the investors cannot adapt timely, their performance in market can be regarded as market anomalies.

The recent studies of AMH focus on conducting empirical research for proving whether the statements of AMH can be observed in various markets. Urquhart and McGroarty [2], Okorie and Lin [3] found the timevarying return predictability in market conditions. Moreover, some researchers analyzed the stock market data from developed countries and regions, summarized the roles of changing market conditions on return predictability and risk preferences [4]. In terms of developing and emerging markets, Xiong et al. found that return predictability and the profitability of the investment strategies can also fluctuate from periods to periods in Chinese stock market [5].

Although so many evidences can prove the validity of $\mathrm{AMH}$, the limitations of AMH can also be found. Ghazani and Ebrahimi' s research showed us the fact that the degree of conformity with AMH decreases if lengthening the window lengths [6]. Some critics also argued that $\mathrm{AMH}$ theory is a philosophical qualitative model instead of quantitative one [7]. All these criticisms imply that AMH is still a developing theory; the framework can be further refined.

Market efficiency varied with market conditions has always been the hot spot issues for the economists. With the aim of summarizing recent progress and addressed the research prospects of $\mathrm{AMH}$, this paper first introduces the development of $\mathrm{AMH}$, and then summarizes the evidence of its applications. Finally, the limitations of AMH theory by some research results have been discussed to indicate the extant flaws of AMH theory. 
The reminder of this paper is organized as follows: Section 2 reviews development from $\mathrm{EMH}$ to $\mathrm{AMH}$; Section 3 introduces the empirical results from other scholars' researches that can certify the existence of $\mathrm{AMH}$; Section 4 introduces the evidence about the limitations of the current AMH theory; Section 5 concludes.

\section{DEVELOPMENT FROM EMH TO AMH}

\subsection{The theory of EMH}

For a long time, whether the market is efficient or not has been a main argument for a number of scholars of finance and economy. According to the Efficient Markets Hypothesis (EMH) proposed by Fama, all market participants are invariably rational and always make the optimal decisions to maximize their profit in any situations [8]. Moreover, the stock price will instantaneously and fully incorporate all of the information available, which implies that the variation of price is in conformity with random walk. As a result, investors are incapable to predict future stock price. Hence, technical analysis is completely ineffective as well as fundamental analysis, and there is no opportunity for arbitrageurs to obtain excess return.

However, Grossman and Stiglitz have argued that a perfect efficient market did not exist, since traders cannot achieve compensation to cover the costs of acquiring information [9]. In recent years, some proponents of behavioral finance cited examples to argue that there did exist an amount of behavioral biases making the market inefficiency, for instance, overconfidence, overreaction, prospect theory and presentativeness bias [10-13], which were contradict with the assumption of individual rationality stated by the EMH.

\subsection{The theory of $A M H$}

For the purpose of reconciling these two opposing perspectives and interpreting the existing anomalies in markets, Lo set up a new theory based on an evolutionary perspective, namely AMH [5, 14]. His new theory is viewed as a reformed version of EMH. The primary framework of the AMH consists of following ideas: (1) Individuals act in their own self-interest. (2) Individuals make mistakes. (3) Individuals learn and adapt. (4) Competition drives adaptation and innovation. (5) Natural selection shapes market ecology. (6) Evolution determines market dynamics.

In his new theory, Lo argues that market efficiency is not an all-or-nothing matter, which is a conventional perception. He states the extent of market efficiency fluctuating with time and market conditions. What is more, the main distinctions from EMH to AMH are derived from the second and third items of the above primary framework [5]. In EMH theory, investors will never make mistakes, any decisions they make are the optimal ones, which were contradict with AMH. Moreover, the business conditions in EMH are eternally steady so that investors are not required to learn and adapt to it. But what implies in $\mathrm{AMH}$ is that the business conditions are constantly dynamic under the influence of business cycles, panics, bubbles, market crashes, global macroeconomic events and other factors. In consequence of the desire of survival in the dynamic market conditions, investors are driven to learn and adapt persistently for receiving reinforcement. However, investors cannot always adapt themselves promptly, since their personal capabilities are limited. And that is the reason why they make mistakes and how behavioral biases arise. Apart from that, an important implication of $\mathrm{AMH}$ is that return predictability can arise from time to time due to the changing business condition [5]. On the contrary, the return predictability doesn' $t$ exist according to the fundamental assumptions of EMH. Based on this, the arbitrage opportunities will eliminate and disappear eventually. However, in the statement of $\mathrm{AMH}$, strategies designed for arbitrage may decline for a time and then return to profitability when business conditions become more conducive to such trades [5].

The recent studies of AMH mostly focus on verifying its existence by seeking the evidence of the periodic and varied return predictability and explaining the role of time-varying market conditions on market prices. Numerous evidences of AMH have been found in a variety of markets in the previous studies. However, some scholars also found evidence in certain markets that there are still some limitations for the theory of AMH [6].

\section{EVIDENCE OF AMH}

In recent years, evidence supporting AMH has been found in different markets. Urquhart and McGroarty found that return predictability fluctuates over time in each market, and they also found that markets do not evolve identically over time and the predictability in the markets is not correlated, different markets can react differently even to the same market condition [2]. As a result, it is advised to view different markets as individual entities [2]. And the result of their research is consistent with the work of Okorie and Lin [3], who verified the impact of the COVID-19 pandemic on the level of information efficiency of four different stock markets around the world. According to their research, the variations of information efficiency in different markets are diverse [3].

\subsection{Stock market}

About the evidence of AMH in the stock market, Kim et al. [14] found strong evidence of time-varying 
return predictability which is driven largely by changing market conditions, as implied by the AMH. In particular, during stock market crashes (1929 and 1987), no return predictability is observed, but an extreme degree of uncertainty is associated with return predictability. By contrast, during fundamental economic or political crises, the stock returns are highly predictable with a moderate degree of uncertainty. During economic bubbles, the degree of return predictability and the associated uncertainty are smaller than normal times [14]. In recent years, a number of evidence of AMH has been exposed from the empirical studies of stock markets in both the developed and developing countries and regions.

\subsubsection{Developed countries and regions}

Boya [15] used the weekly date of the major index of the French stock market from 1988 to 2018 to examine its efficiency and indicated that French stock exchange is broadly efficient but interrupted by periods of inefficiency. Furthermore, the periods with lower efficiency are associated with major reliable events [15]. According to Shah and Bahru's paper, their study verified the AMH for the US (Dow Jones and S\&P 500) and Hong Kong (Hang Seng) stock markets by testing daily and weekly data for the return predictability for the 20-year study course [16]. The indices exhibited the time-varying risk premia and risk return characteristic (Sharpe ratio), indicating that risk preferences are adaptive to the changing market conditions [16]. Ali Almail and Fahad Almudhaf extend and complement Charles et al. [17] and Urquhart and Hudson [18] by examining the efficiency of UK stock market and currency during the last three centuries. Using both AVR and AQ tests, they find evidence of time-varying degree of efficiency which supports the AMH [19]. Todea et al. [20] investigated the profitability of an optimum moving average strategy selected from 15,000 combinations on the main European capital markets and found the empirical results are consistent with the assumptions of $\mathrm{AMH}$ in terms of the fact that profit opportunities do exist from time to time. Moreover, the paper proves that the profitability of those strategies is mainly due to nonlinear episodic dependencies [20].

\subsubsection{Developing countries}

Xiong et al. verified the existence of calendar effect by observing and analysing the daily returns of the four indices of Chinese stock markets by using GARCH $(1,1)$ model [21]. They found that the returns for the calendar effect are significantly different from other periods. And the profitability of the investment strategies they constructed on the calendar effect is observed to fluctuate as time varies, which is a strong evidence of AMH [21]. In the study of evaluating the return predictability of Dow Jones Islamic, conventional size and sector-indices, Charles and Kim found that time-varying return predictability existed in both Islamic and conventional sub-indices, which is also consistent with the assumption of AMH [4]. The paper conducted by Zhu uses the Shanghai Composite Index and Shenzhen Composite Index from two Chinese stock markets and adopts AR (1) model, ARIMA model, variance ratio test and automatic portmanteau test with rolling windows to test time-varying efficiency of Chinese markets [5]. On the other hand, GARCH model is adopted to study the dynamic relationship between return and risk with analysis of the mechanism behind the market. The results of the research supported AMH theory: the results of the full sample test showed that the Chinese market as a whole is inefficient, and there is no trend of efficiency growing monotonously. Although most results of sub-sample analysis demonstrate weakform market efficiency, there exist numerous periods with predictable return, which demonstrates a two-orthree-year cycle [5]. In a word, the evidence of AMH with multiple forms can be observed in a variety of financial markets.

\subsection{Bond market}

Recently, studies on market efficiency were principally focused on stock markets. The empirical studies on bond markets are less abundant than those on stock markets. The paper published by Charfeddine et al. empirically investigated the AMH in two of the most established bond markets in the world: the US and UK, and two of the emerging markets: South Africa and India, using monthly data series spanning long time periods [22]. The main findings of the paper were that all of the four government bond markets showed that the degree of market efficiency changed overtime, due to changing market conditions and institutional factors, which is consistent with the implications of the AMH. Furthermore, it was found that the degree of return predictability depended heavily on the prevailing economic, political and market conditions, consistent with the implications of the AMH. Overall, the results suggested that the AMH provides a better description of the behaviour of government bond returns than the EMH [22].

\subsection{Foreign exchange market}

Christopher et al. analysed the intertemporal stability of excess returns to technical trading rules in the foreign exchange market by conducting true, out-of-sample tests on previously studied rules and their findings are consistent with the AMH instead of the EMH [23]. The rather slow speed with which the market appeared to take advantage of the documented profit opportunities may be explained in part by the fact that an effective investment strategy required trading rule returns combined with a diversified stock portfolio. They 
conjectured that both institutional and behavioural factors might have delayed the implementation of such strategies [23]. Another paper conducted by Charles et al. examined return predictability of major foreign exchange rates by testing for martingale difference hypothesis (MDH) using daily and weekly data from 1975 to 2009 [17]. Although exchange rate returns have been found to be unpredictable most of time, they observed episodes of statistically significant return predictability which are closely associated with the major events such as coordinated central bank interventions and the financial crises. This finding suggests that return predictability of foreign exchange rates occurs from time to time depending on changing market conditions, which is consistent with the implications of the AMH. That is, dynamic market conditions govern the degree of efficiency of foreign exchange markets [17].

\subsection{Other relevant markets}

Bitcoin has received substantial attention from investors, speculators, and policymakers. As on 26 December 2017, it topped 1382 cryptocurrencies in market capitalization and volume of trade, and had 44.8 percent market share (Cryptocurrency Market Capitalizations, 2017). Khuntia and Pattanayak [24] have used the AMH framework, for the first time, to assess the evolution of bitcoin, the most popular digital currency. This study evaluated the AMH and evolving return predictability in bitcoin market. Two robust methods were used in a rolling-window framework to capture time-varying linear and nonlinear dependence in bitcoin returns. They found that market efficiency evolves with time, which support the AMH in bitcoin market [24]. In terms of oil markets, a focus of interest is on the informational efficiency due to oil price fluctuations greatly affect the functioning of most economic sectors at various levels and via different channels (Lescaroux and Mignon, 2008).Majid Mirzaee Ghazani and Seyed Babak Ebrahimi have examined the Adaptive Market Hypothesis (AMH) by using daily historical data for the three benchmark crude oils(including of WTI, Brent and OPEC basket). Also, to evaluate any changes in market efficiency and evolution of market behaviour over the time and track the time variation of efficiency in crude oils; they used a rolling-sample method with different window lengths that is consistent with the Adaptive Market Hypothesis (AMH) [6]. All in all, evidence in support of AMH's claims was found in other relevant markets.

\section{LIMITATION OF AMH}

Although Adaptive Market Hypothesis by Lo can reconcile Efficient Market Hypothesis with behavioral finance and can be confirmed by many cases in finance markets, AMH still has its limitations and imperfections.

One of the evidences for the limitations is from the benchmark crude oil of OPEC basket market. Ghazani and Ebrahimi [6] examined the existence of adaptive market hypothesis (AMH) through analyzing daily returns on the three benchmark crude oils, which were West Texas Intermediate (WTI), Brent and OPEC basket. They used Automatic Portmanteau (AQ) and Generalized Spectral (GS) to test linear and nonlinear dependency of the historical return data of the daily bench crude oil from 2003 to 2018. Moreover, a rollingsample method with different window lengths is applied to evaluate any changes in market efficiency and evolution of market behavior over the time and track the time variation of efficiency in crude oils. Although the results show that market conditions for WTI and Brent are consistent with the implication of $\mathrm{AMH}$, the degree of conformity with AMH decreases when lengthening the window lengths from 100 to 500 days for the OPEC basket data, which is an evidence that AMH has its own limitation and is not absolutely perfect. One of the possible reasons is the declining of OPEC influence in the oil market in accord with fading of its market power in the last decade. Another one is related to the Arab spring and advent of chaos in some OPEC member countries like Libya, Venezuela and also sanctions against Iran for its nuclear program. There could be further reasons that the Brent and WTI crude oil markets have well-established oil futures and derivatives markets relative to OPEC oil basket and that some OPEC member countries have some structural weaknesses like infrastructure logistics and storage capacities.

The other one is the limitation of $\mathrm{AMH}$ in assumption. According to Pal [25], AMH is a philosophical qualitative model instead of quantitative. Although the idea of AMH is right that market efficiency cannot be evaluated in a vacuum and is highly context-dependent and dynamic, the given assumption of informational inefficiency for $\mathrm{AMH}$ is not correct. AMH relies on a subjective discourse to explain the information inefficiency instead of reconciling it with information efficiency like EMH. It leads to choosing to stick to understanding behavioral limitations as a lack of human innovation rather than considering behavior subsumed and driven by a statistical framework despite the fact that $\mathrm{AMH}$ illustrates well the temporal limitation of the behavioral model. And AMH diverges away from system thinking as preference is consumed to be driving the system rather than be driven by it. Moreover, although Lo uses the present value generalization driving the market price to generate a statistical evidence (variance ratio) to challenge EMH and then chooses to stick to evolutionary subjectivity as a basis for AMH, Lo ignores to extend statistical thinking to back his case for 
$\mathrm{AMH}$ and picks up selective ideas to back his evolutionary view. Lo ignores informational reconciliation, illustrates the temporal reality of risk, gives an emotional reason for risks, labels all of this as natural, calls it evolutionary and suggests adaptability and innovation without defining and stating the functioning of the contextual dependent. As a result, Pal considers dynamic system in AMH as philosophy, not science.

\section{CONCLUSION}

By reviewing a large number of previous documents, this article first introduces the development of theories from EMH to AMH, expounds the differences in assumptions between EMH and AMH; then this paper lists the evidence of $\mathrm{AMH}$ indifferent financial markets (including stock market, bond market and foreign exchange market) and other related markets (including bitcoin market and crude oil market); finally, some evidence and discussion for the limitations of AMH have been found. In summary, this paper concludes that although AMH has its limitations and needs to be improved as an unsystematic theory, compared with EMH, AMH can better describe the real situations of financial markets and other related markets than EMH. However, it is a qualitative method, it is necessary to establish a quantitative model for the $\mathrm{AMH}$ theory in the future research. This paper may be helpful for those who are interested in AMH and want to carry out AMH related research.

\section{REFERENCES}

[1] Lo, A.W., (2005). Reconciling efficient markets with behavioral finance: the Adaptive Markets Hypothesis. J. Invest. Consult. 31 (1), 21-44 Social Science Electronic Publishing. DOI: https://doi.org/10.3905/jpm.2004.443340

[2] Urquhart, A., \& Mcgroarty, F. (2016). Are stock markets really efficient? evidence of the adaptive market hypothesis. International Review of Financial Analysis, 47, 39-49. DOI: https://doi.org/10.1016/j.irfa.2016.06.011

[3] Okorie, D. I., \& Lin, B. (2021). Adaptive market hypothesis: the story of the stock markets and covid-19 pandemic. The North American Journal of Economics and Finance, 57(332), 101397. DOI: https://doi.org/10.1016/j.najef.2021.101397

[4] Charles, A., O Darné, \& Kim, J. H. (2017). Adaptive markets hypothesis for islamic stock indices: evidence from dow jones size and sectorindices. International Economics, 151, 100-112. DOI: https://doi.org/10.1016/j.inteco.2017.05.002
[5] Zhu, Z. (2017). Time-varying efficiency and the adaptive market hypothesis: evidence from chinese a-share stock market. SSRN Electronic Journal. DOI: https://doi.org/10.2139/ssrn.3471649

[6] Ghazani, M. M., \& Ebrahimi, S. B. (2019). Testing the adaptive market hypothesis as an evolutionary perspective on market efficiency: evidence from the crude oil prices. Finance Research Letters. DOI: https://doi.org/ 10.1016/j.frl.2019.03.032

[7] Pal, M. (2016). Adaptive market hypothesis (study of assumptions). SSRN Electronic Journal. DOI: https://doi.org/10.2139/ssrn.2742496

[8] Fama, E.F., (1970). Efficient capital markets: a review of theory and empirical work. J. Finance 25 (2), 383-417. DOI: https://doi.org/10.1111/j.15406261.1970.tb00518.x

[9] Grossman, S.J., Stiglitz, J.E., (1980). On the impossibility of informationally efficient markets. Am. Econ. Rev. 70 (3), 393-408.

[10] Barber, B. and T. Odean, T., (2001), "Boys Will Be Boys: Gender, Overconfidence, and Common Stock Investment", Quarterly Journal of Economics 116, 261-229. DOI: https://doi.org/ $10.2139 /$ ssrn. 139415

[11] DeBondt, W. and R. Thaler., (1986), "Does the Stock Market Overreact?", Journal of Finance 40, 793-807. DOI: https://doi.org/10.2307/2327804

[12] Kahneman, D. and A. Tversky., (1979), "Prospect Theory: An Analysis of Decision Under Risk", Econometrica 47, 263-291. DOI: https://doi.org/10.2307/1914185

[13] Kahneman, D. and S.Frederick. ,(2002), Representativeness revisited: Attribute substitution in intuitive judgment, Heuristics and Biases (The Psychology of Intuitive Judgment)

[14] Kim, J. H., Shamsuddin, A., \& Lim, K. P. (2011). Stock return predictability and the adaptive markets hypothesis: evidence from century-long u.s. data. Journal of Empirical Finance, 18(5), 868879. DOI: https://doi.org/ 10.1016/j.jempfin.2011.08.002

[15] Boya, C. M. (2019). From efficient markets to adaptive markets: evidence from the french stock exchange. Research in International Business and Finance, 49, 156-165. DOI: https://doi.org/ 10.1016/j.ribaf.2019.03.005

[16] Shah, A., \& Bahri, A. Are stock markets adaptive? evidence from us, hong kong and india. Social Science Electronic Publishing. DOI: https://doi.org/10.2139/ssrn.3316877 
[17] Charles, A., O Darné, \& Kim, J. H. (2010). Exchange-rate return predictability and the adaptive markets hypothesis: evidence from major foreign exchange rates. Working Papers, 31(6), 1607-1626. DOI: https://doi.org/ 10.1016/j.jimonfin.2012.03.003

[18] Urquhart, A. and Hudson, R. (2013) Efficient or adaptive markets? Evidence from major stock markets using very long run historic data, International Review of Financial Analysis, 28, 130-142. DOI: https://doi.org/ 10.1016/j.irfa.2013.03.005

[19] Almail, A., \& F Almudhaf. (2017). Adaptive market hypothesis: evidence from three centuries of uk data. Economics \& Business Letters, 6(2), págs. 48-53.

DOI: https://doi.org/10.17811/ebl.6.2.2017.48-53

[20] Todea, A., Zoicas-Ienciu, A., \& Filip, A. M. (2009). Profitability of the moving average strategy and the episodic dependencies: empirical evidence from european stock. European Research Studies Journal, XII(1), 63-72.
[21] Xiong, X., Meng, Y., Li, X., \& Shen, D. (2018). An empirical analysis of the adaptive market hypothesis with calendar effects: evidence from china. Finance Research Letters. DOI: https://doi.org/10.1016/j.frl.2018.11.020

[22] Charfeddine, L., Khediri, K. B., Aye, G. C., \& Gupta, R. (2017). Time-varying efficiency of developed and emerging bond markets: evidence from long-spans of historical data. Physica A Statistical Mechanics \& Its Applications, 505, 632647. DOI: https://doi.org/ 10.1016/j.physa.2018.04.004

[23] Neely, C. J., Weller, P. A., \& Ulrich, J. The adaptive markets hypothesis: evidence from the foreign exchange market. Social Science Electronic Publishing. DOI: https://doi.org/ 10.2139/ssrn.922345

[24] Khuntia, S., \& Pattanayak, J. K. (2018). Adaptive market hypothesis and evolving predictability of bitcoin. Economics Letters, 167(JUN.), 26-28. DOI: https://doi.org/ 10.1016/j.econlet.2018.03.005

[25] Lo, A.W., (2004). The adaptive markets hypothesis. J. Portf. Manag. 30 (5), 15-29. DOI: https://doi.org/10.3905/jpm.2004.442611 